\title{
H-Ras mutation modulates the expression of major cell cycle regulatory proteins and disease prognosis in oral carcinoma
}

\author{
KM Sathyan ${ }^{1}$, KR Nalinakumari ${ }^{2}$ and S Kannan ${ }^{1}$ \\ ${ }^{1}$ Laboratory of Cell Cycle Regulation and Molecular Oncology, Division of Cancer Research, Regional Cancer \\ Centre, Thiruvananthapuram, Kerala, India and ${ }^{2}$ Division of Dental Surgery, Regional Cancer Centre, \\ Thiruvananthapuram, Kerala, India
}

\begin{abstract}
Activating mutations of the Ras is a moderately frequent event in oral carcinogenesis in Indian patients. Ras pathway has essential roles in regulation of various phases of the cell cycle, especially at $G_{1}$ phase. Despite a large body of in vitro evidence, the multidimensional interaction between mutated Ras pathway and $G_{1}$ cell cycle regulatory proteins in tumours in vivo is poorly determined. In the present study, DNA samples were screened for mutations in hot spot exons of B-Raf and hot spot codons 12, 13 and 61 of $\mathrm{H}-$, $\mathrm{K}-$ and $\mathrm{N}-\mathrm{Ras}$ by PCR-SSCP. Mutations were confirmed by direct sequencing. Expression of $G_{1}$ cell cycle regulatory proteinscyclin D1, CDK4, Rb, p53, p16 and p21 and proliferation marker PCNA was analysed immunohistochemically. The results revealed the absence of $B$-Raf mutations in oral carcinoma in spite of $12.5 \%$ of the samples showing H-Ras mutation. The H-Ras mutant cases showed significantly low cyclin D1 $(P=0.027)$ and CDK4 $(P=0.046)$ expression and overexpression of $\mathrm{Rb}(P=0.011)$ and $\mathrm{p} 16(P=0.026)$. H-Ras mutant carriers also had significantly high recurrence-free survival $(P=0.033)$. In summary the present study demonstrated an epistatic interaction between $\mathrm{H}-\mathrm{Ras}$ mutation and $\mathrm{G}_{1}$ cell cycle regulatory proteins in vivo. $\mathrm{H}$-Ras mutation, thus, defines a molecular subtype of oral carcinoma with favourable outcome and unique biology.

Modern Pathology (2007) 20, 1141-1148; doi:10.1038/modpathol.3800948; published online 31 August 2007
\end{abstract}

Keywords: Ras mutation; B-Raf mutation; cell cycle; cyclin D1; p16; Rb

Oral squamous cell carcinoma is the most common cancer of the head and neck region and it accounts for 274000 new cancer cases and almost 145000 deaths annually. ${ }^{1}$ World wide, the incidence of oral cancer varies greatly and high incidence is seen in India and other parts of Asia, France and Brazil. ${ }^{2}$ The differing social customs, genetic and environmental factors are likely responsible for this geographical variation in incidence. ${ }^{2}$ The aetiological difference is also reflected in genetic aberrations between oral cancers from the Western and South East Asian countries. In Indian oral cancers, a high prevalence of Ras and a lower incidence of p53 mutations were reported than in Western cases. $^{3}$ Despite radical changes in the therapeutic management of oral cancer, the overall survival rates have not improved over 30 years and remain unsatisfactory. ${ }^{4}$

Correspondence: Dr S Kannan, PhD, Laboratory of Cell Cycle Regulation and Molecular Oncology, Division of Cancer Research, Regional Cancer Centre, Thiruvananthapuram 695011, India.

E-mails: kannan@rcctvm.org or kannan_rcc@yahoo.com

Received 04 April 2007; accepted 16 July 2007; published online 31 August 2007
The Ras-Raf-MEK-ERK-MAP kinase signalling transduction pathway regulates cell cycle progression and apoptosis in diverse types of cells. ${ }^{5}$ The Ras-Raf-MEK-ERK signalling cascade is now established as an important target in cancer therapy. ${ }^{6}$ At least $30 \%$ of human tumours contain mutation in one of the three Ras genes; K-, N- and H-Ras. ${ }^{7}$ The mutation at codons 12, 13 and 61 leads to constitutive activation of the downstream signalling driven by Ras. In oral carcinomas, the frequency of Ras mutation showed great demographic variation. Ras mutation has been reported in $20-35 \%$ of the cases from India, ${ }^{8-10}$ whereas lower frequencies (4\%) were reported from the United Kingdom ${ }^{11}$ and no mutation was reported from the Unites States. ${ }^{12}$ Davies et $a 1^{13}$ revealed activating mutations in the B-Raf kinase gene in greater than $60 \%$ of melanomas and a broad range of other cancers. Even though only less than $1 \%$ of the cancer samples have concurrent B-Raf and Ras mutations, an apparent trend was observed in which the type of tumours with B-Raf mutations are similar to those with Ras mutation. ${ }^{13}$ In head and neck carcinoma, B-Raf mutation was reported to be a rare event and was found only in 
pharyngeal region. ${ }^{14}$ Even though Ras mutations are highly prevalent in Indian oral carcinoma, B-Raf mutation has not been investigated. Hence, we hypothesize that B-Raf mutations can also play a role in oral carcinogenesis in the Indian scenario.

Ras proteins have essential roles in controlling the activity of multiple downstream effector pathways that regulate normal cellular proliferation. ${ }^{6}$ Ras-controlled pathways modulate several transcription factors that eventually link Ras activity to various phases of the cell cycle. ${ }^{5}$ Oncogenic Ras efficiently transform immortal rodent and human cell line but fails to transform primary cells. ${ }^{15,16}$ In primary rat Schawnn cells, oncogenic Ras causes premature $G_{1}$ arrest and senescence mediated by the induction of p15, p16 and p21. ${ }^{17}$ This indicates that additional genetic events are required in order for Ras to be transforming. Loss of the $\mathrm{Rb}$ family or $\mathrm{p} 16^{\mathrm{INK} 4 \mathrm{~A}}$ together with p53 loss, enables Ras signals to transform normal cells. ${ }^{18}$ It has been shown that activation of Ras results in increased levels of cyclin D1. ${ }^{19}$ The consequential increase in cyclin D1/CDK4 or CDK6 complex in turn inactivates $\mathrm{Rb}$ function and thus abrogates $\mathrm{G}_{1}$ restriction point. Thus, Rb and p53 pathways play a critical role in the Ras-mediated oncogenesis. ${ }^{20}$ Despite the large body of in vitro evidence, the multidimensional interaction between mutant Ras pathway and $G_{1}$ cell cycle regulatory proteins is poorly determined in tumours in vivo. In the present study, we have analysed cooperative interaction between Ras and B-Raf genes in oral carcinogenesis in Indian patients. Moreover, the biological consequence of the activating mutations in these genes on key $G_{1}$ cell cycle regulatory proteins and their prognostic significance were characterized.

\section{Materials and methods}

A total of 152 oral squamous cell carcinoma patients were studied from our original cohort of 348 patients described previously. ${ }^{21}$ Availability of tumour biopsy for DNA isolation was the criteria for selecting the present cohort from the original one. The clinical findings, treatment and follow-up have been recorded prospectively. The clinical and pathological features of the patients are summarized in Table 1. An incision biopsy of tumour tissue was collected from each eligible patient before treatment. Criteria for histological diagnosis were based upon WHO guidelines for the histological classification of oral lesions. There were 51 female $(33.6 \%)$ and 101 male $(66.4 \%)$ patients. Clinical follow-up of all these patients after treatment were carried out until death or up to a maximum of 50 months with a median follow-up of 22 months. The Institute's Research Review Board and the Human Ethics Committee approved the present study.
Table 1 Clinicopathological characteristics of the patients

\begin{tabular}{|c|c|}
\hline Factors & Frequency (\%) \\
\hline \multicolumn{2}{|l|}{ Sex } \\
\hline Male & $101(66.4)$ \\
\hline Female & $51(33.6)$ \\
\hline \multicolumn{2}{|l|}{ Age (mean+s.d.; range) } \\
\hline Male & $58 \pm 10(39-83)$ \\
\hline Female & $60 \pm 0(36-80)$ \\
\hline \multicolumn{2}{|l|}{ Oral habits } \\
\hline No oral habits & $10(6.6)$ \\
\hline Chewing alone & $51(33.8)$ \\
\hline Smoking alone & $6(4.0)$ \\
\hline Alcohol alone & $1(0.7)$ \\
\hline Chewing with smoking & $22(14.6)$ \\
\hline Chewing with alcohol & $12(7.9)$ \\
\hline Smoking with alcohol & $9(6.0)$ \\
\hline Chewing+smoking+alcohol & $40(26.5)$ \\
\hline NA & 1 \\
\hline \multicolumn{2}{|l|}{ Site of disease } \\
\hline Tongue & $34(22.4)$ \\
\hline Other sites & $118(77.6)$ \\
\hline \multicolumn{2}{|l|}{ T-status } \\
\hline 1 & $12(8.2)$ \\
\hline 2 & $51(34.7)$ \\
\hline 3 & $26(17.7)$ \\
\hline 4 & $58(39.5)$ \\
\hline NA & 5 \\
\hline \multicolumn{2}{|l|}{$N$-status } \\
\hline Absent & $82(60.7)$ \\
\hline Present & $63(39.3)$ \\
\hline NA & 7 \\
\hline \multicolumn{2}{|l|}{ Composite stage } \\
\hline I & $10(6.8)$ \\
\hline II & $34(23.1)$ \\
\hline III & $42(28.6)$ \\
\hline IV & $61(41.5)$ \\
\hline NA & 5 \\
\hline \multicolumn{2}{|l|}{ Histopathology } \\
\hline WDSCC & $46(30.5)$ \\
\hline MDSCC & $90(59.3)$ \\
\hline PDSCC & $8(5.1)$ \\
\hline Verrucous $\mathrm{Ca}$ & $8(5.1)$ \\
\hline \multicolumn{2}{|l|}{ Treatment } \\
\hline Radiotherapy (R) & $81(53.3)$ \\
\hline Surgery (S) & $3(2.0)$ \\
\hline Chemotherapy (C) & $6(3.9)$ \\
\hline $\mathrm{R}+\mathrm{S}$ & $32(21.1)$ \\
\hline $\mathrm{C}+\mathrm{R}$ & $17(11.2)$ \\
\hline $\mathrm{C}+\mathrm{R}+\mathrm{S}$ & $13(8.6)$ \\
\hline
\end{tabular}

NA, not available.

\section{Mutation Analysis of B-Raf and Ras Genes}

DNA from tissue samples and blood was extracted using standard phenol-chloroform method. B-Raf mutation was reported to confine to the exons 11 and $15 .{ }^{13}$ DNA samples were screened for mutations within these regions of $\mathrm{B}-\mathrm{Raf}^{22}$ and hot-spot codons 12, 13 and 61 of all three Ras genes by PCRSSCP. $^{23-27}$ The positive controls used for the B-Raf 
mutations analyses were, exon 15-NPA cell lines, $1205 \mathrm{Lu}$ and a mutation confirmed papillary thyroid tumour DNA and for exon 11 was NCI-1755 cell line. For Ras mutation analyses T24 (H-Ras exon 1), A431, SW480 (both for K-Ras exon 1), MOLT4 (NRas exon 1) and HL60 (N-Ras exon 2) cell lines were used. Normal blood DNA as well as placental DNA was included as wild-type control for SSCP. Following amplification, $9 \mu \mathrm{l}$ of the PCR product was mixed with an equal volume of loading buffer containing $95 \%$ formamide, $10 \mathrm{mM} \mathrm{NaOH}, 0.25 \%$ bromophenol blue and $0.25 \%$ xylene cyanol. The mixture was denatured at $95^{\circ} \mathrm{C}$ for $10 \mathrm{~min}$ and then quickly cooled on ice. The whole mixture was then loaded on $5-8 \%$ non-denaturing polyacrylamide gel (bisacrylamide:acrylamide ratio-1:49) with or without $5 \%$ glycerol and respectively run at room temperature or $4^{\circ} \mathrm{C}(300 \mathrm{~V})$ for $12-14 \mathrm{~h}$. After electrophoresis, the bands were visualized by silver staining.

\section{Direct DNA Sequencing}

All samples exhibiting mobility shifts in SSCP were re-amplified from genomic DNA using the same sets of primers. The PCR products were gel purified and sequenced with ABI Big Dye Terminator Cycle Sequencing Kit (Applied Biosystems, Rotkreuz, Switzerland) and analysed in the ABI prism 377 Automated DNA sequencer. The sequencing was carried out from both sense and antisense orientation for confirmation.

\section{Immunohistochemistry}

Immunohistochemical expression of cell cycle regulatory proteins-cyclin D1, CDK4, Rb, p16, p53, p21 and proliferation marker PCNA in these samples were reported previously. ${ }^{21}$ Standard avidinbiotin complex (ABC) method was employed for immunohistochemical studies. ${ }^{21}$ Briefly, $5 \mu \mathrm{m}$ thick tissue sections were cut from buffered formalinfixed, paraffin-embedded tissues. After blocking the nonspecific sites, the sections were incubated overnight at $4^{\circ} \mathrm{C}$ with optimally diluted respective primary antibodies: Rb (clone IF8), cyclin D1 (clone DCS6), CDK4 (clone DCS35), p16 (clone ZJ14), p53 (clones DO7 and PAb240), p21 (clone DCS60.2) and PCNA (clone PC10). All the antisera were purchased from Neomarkers, CA, USA. The antibody-bound sites were visualized using an avidinbiotin-immunoperoxidase system (VectaElite, Vector Laboratories Inc., Burlingame, CA, USA) with diaminobenzidine and nickel intensification (Vector Laboratories Inc.) and counterstained with haematoxylin. Negative controls (with diluted nonimmune mouse sera instead of primary antibody) were also run with each sample. The surrounding stromal cells and adjacent normal epithelia present in the sections served as internal controls.
The intensity of staining was evaluated using a four-point semiquantitative scale: $0=$ negative, $2=$ mild, $4=$ moderate and $6=$ intense. Besides the staining intensity, the percentage of positive cells was also noted. For assessing the positivity, the cells seen at the invading tumour front or the deep malignant islands were considered. For analysis, the results were expressed as expression index, that is, the product of percentage of positivity and score of the staining intensity seen in the majority of the cells. For analysis, median of expression index was taken as cutoff point to dichotomize the data. The expression index values above the median were categorized as overexpression and median value or values below the median were considered as low expression. ${ }^{21}$

\section{Statistical Analysis}

Association between mutation and clinical parameters as well as the expression of cell cycle regulatory proteins was analysed by $\chi^{2}$ tests. The univariate survival analyses were carried out using log-rank test. Recurrence-free survival curve was generated by the Kaplan-Meier method. The significance of the difference between the curve was tested by log-rank test. A two-tailed $P$-value $\leq 0.05$ was considered 'statistically significant' in all statistical analysis.

\section{Results}

\section{B-Raf Mutation}

A representative SSCP gel of exon 15 of B-Raf is shown in Figure 1. Despite clear resolution of the positive controls, all oral cancer samples studied, showed only a normal SSCP pattern. Thus, indicating the absence of activating mutations in exons 11 and 15 of B-Raf gene in oral cancer.

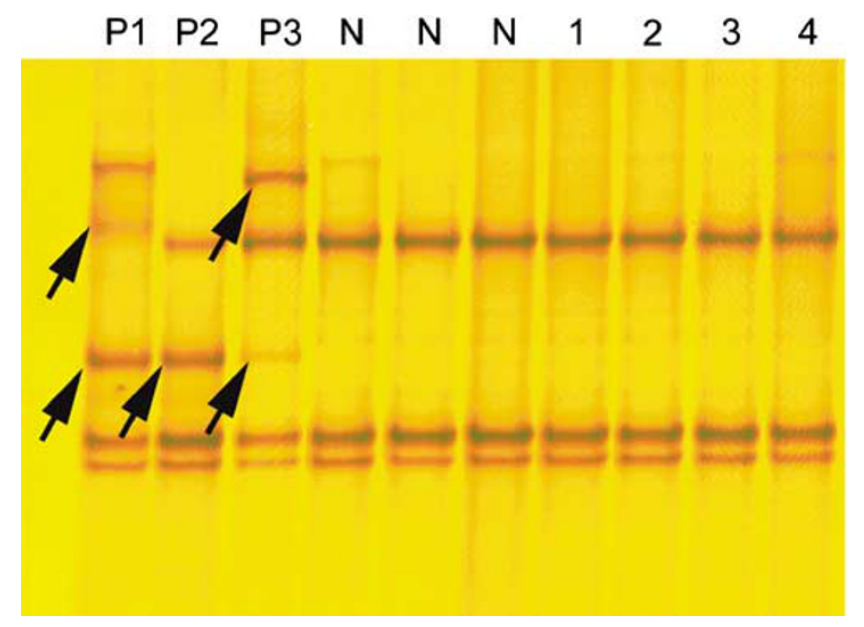

Figure 1 A representative PCR-SSCP gel of mutation analysis of the B-Raf gene exon 15. P1-3 are positive controls; N, normal samples; 1-4, tumour samples; arrows indicate mobility shift. 


\section{Ras Mutation: Clinical and Prognostic Significance}

Among the three Ras genes screened for mutation, only H-Ras showed mutation. In all, 19 samples $(12.5 \%)$ were detected carrying mutation in H-Ras gene (Figure 2). The nature of mutation and aminoacid changes are detailed in Table 2. Majority of mutations were at codon $12(63 \%)$ followed by codon $13(32 \%)$. While only one sample showed codon 61 mutation (5\%). One sample had double mutation at codon 13 (Figure 2b1). Thus, a total of 20 mutations were found in the 19 samples. The clinical significance of these mutations was statistically determined. Significant gender difference was found in the H-Ras mutation (Table 3). Females had comparatively higher percentage of $\mathrm{H}$-Ras mutation. Intraoral site-specific difference in the distribution of H-Ras mutation was also seen. Most of the Ras mutations were at oral sites excluding the tongue (18/19) although only one tongue carcinoma showed Ras mutation ( $P=0.056$; Table 3$)$. H-Ras mutation did not show any significant association with nodal status, tumour size, grade of differentiation and stage of the disease. In survival analysis, a significant relation was noticed for Ras mutation with recurrence-free survival. H-Ras mutation carriers had significantly high recurrence-free survival $(P=0.033)$. Even though not significant, the overall survival was also high in H-Ras mutation carriers. The Kaplan-Meier recurrence-free survival curve for patients according to $\mathrm{H}$-Ras mutation is given in Figure 3.

\section{Association between H-Ras Mutation and $G_{1}$ Cell Cycle Regulators}

The general pattern of immunohistochemical expression of cell cycle regulatory proteins, cyclin D1, CDK4, Rb, p16, p53, p21 and proliferation marker PCNA, in these samples was previously reported. ${ }^{21}$ Briefly, all the examined proteins (except p16) were overexpressed in tumour cells, while p16 exhibited downregulation in the majority of malignant cases. Localization of the studied proteins was primarily nuclear, but, cyclin D1, CDK and p16 also showed some degree of cytoplasmic expression. Expression pattern of p53 was assessed with two clones of
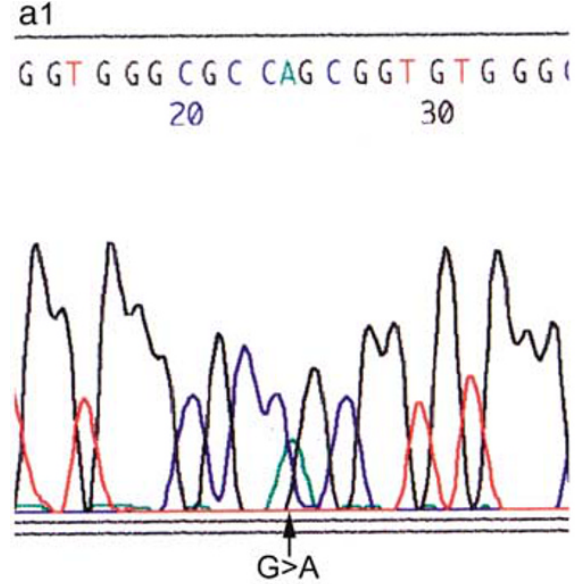

b1

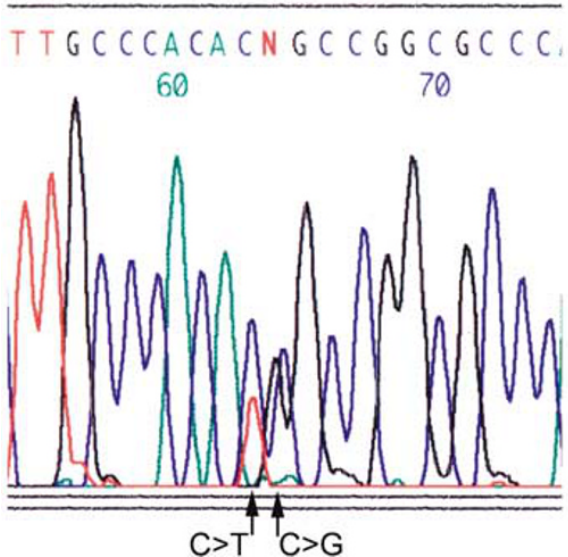

a2

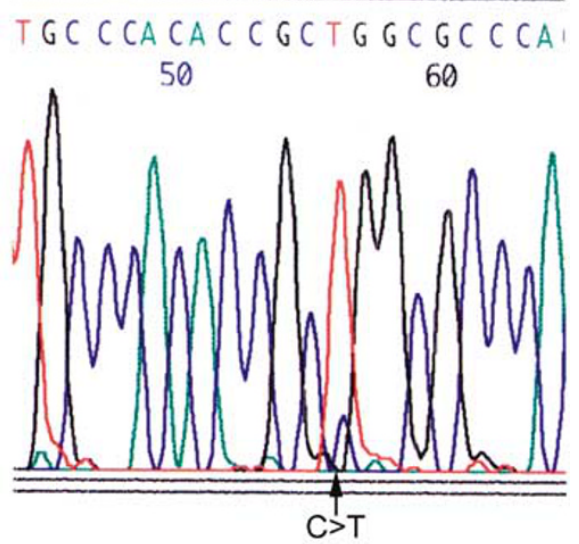

b2
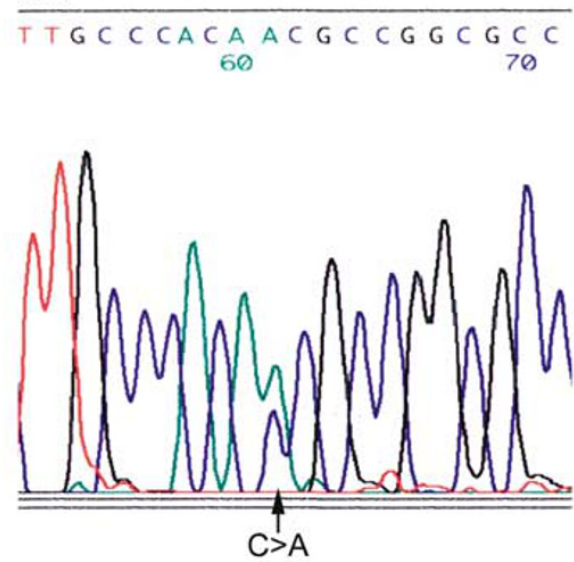

Figure 2 Representative electropherograms of H-Ras mutation analysis. (a1 and a2) -Sense and antisense strands of a sample showing H-Ras codon 12 mutation (GGC-AGC), respectively; (b1)-antisense strand of a sample showing double mutation at codon 13; (b2) - antisense strand of a sample showing a mutation at codon 13. 
Table 2 H-Ras mutations, the amino-acid change, cyclin D1 expression and survival status of the patients are shown

\begin{tabular}{|c|c|c|c|c|c|c|}
\hline Sample no. & Site of tumour & Wild type & Mutation & Amino-acid change & Cyclin D1 expression & Recurrence \\
\hline \multicolumn{7}{|l|}{ Codon 12} \\
\hline 60 & OS & GGC & AGC & Gly $>$ Ser & Low & No \\
\hline 65 & OS & GGC & AGC & Gly $>$ Ser & Low & No \\
\hline 99 & OS & GGC & AGC & Gly $>$ Ser & High & Yes \\
\hline 156 & OS & GGC & GAC & Gly $>$ Asp & Low & No \\
\hline 248 & OS & GGC & AGC & Gly $>$ Ser & Low & No \\
\hline 255 & OS & GGC & AGC & Gly $>$ Ser & Low & No \\
\hline 203 & $\mathrm{~T}$ & GGC & AGC & Gly $>$ Ser & High & No \\
\hline 494 & OS & GGC & AGC & Gly $>$ Ser & Low & No \\
\hline 398 & OS & GGC & AGC & Gly $>$ Ser & Low & No \\
\hline 242 & OS & GGC & AGC & Gly $>$ Ser & High & No \\
\hline 178 & OS & GGC & AGC & Gly $>$ Ser & Low & No \\
\hline 90 & OS & GGC & AGC & Gly $>$ Ser & Low & No \\
\hline \multicolumn{7}{|l|}{ Codon 13} \\
\hline 152 & OS & GGT & TGT & Gly $>$ Cys & Low & No \\
\hline 154 & OS & GGT & GTT & Gly $>$ Val & Low & No \\
\hline 202 & OS & GGT & GTT & Gly $>$ Val & Low & No \\
\hline 237 & OS & GGT & CGT & Gly $>$ Arg & High & No \\
\hline \multirow[t]{2}{*}{260} & OS & GGT & CGT & - & High & No \\
\hline & & & GAT & - & & \\
\hline 153 & OS & GGT & GTT & Gly $>$ Val & Low & No \\
\hline \multicolumn{7}{|l|}{ Codon 61} \\
\hline 140 & OS & CAG & CTG & Gly $>$ Leu & Low & No \\
\hline
\end{tabular}

OS, oral sites excluding tongue; $\mathrm{T}$, tongue.

Table 3 Variables showed significant association with H-Ras mutation

\begin{tabular}{|c|c|c|c|c|}
\hline \multirow[t]{2}{*}{ Variables } & \multicolumn{2}{|c|}{ H-Ras mutation } & \multirow[t]{2}{*}{$\chi^{2} \mathrm{P}$-value } & \multirow{2}{*}{$\begin{array}{c}\text { Relative risk and 95\% } \\
\text { confidence interval }\end{array}$} \\
\hline & No mutation & Mutation & & \\
\hline \multicolumn{5}{|l|}{ Gender } \\
\hline Male & 93 (92.1) & $8(7.9)$ & & \\
\hline Female & $40(78.6)$ & $11(21.6)$ & 0.016 & $3.2(1.196-8.546)$ \\
\hline \multicolumn{5}{|l|}{ Oral sites } \\
\hline Other oral sites & $100(84.7)$ & $18(15.3)$ & & \\
\hline Tongue & $33(97.1)$ & $1(2.9)$ & 0.056 & $0.168(0.022-1.310)$ \\
\hline \multicolumn{5}{|l|}{ Cyclin D1 } \\
\hline Low expression & $61(81.3)$ & $14(18.7)$ & & \\
\hline High expression & $70(93.3)$ & $5(6.7)$ & 0.027 & $0.311(0.106-0.914)$ \\
\hline \multicolumn{5}{|l|}{ CDK4 } \\
\hline Low expression & $65(82.3)$ & $14(17.7)$ & & \\
\hline High expression & $67(93.1)$ & $5(6.9)$ & 0.046 & $0.346(0.118-1.017)$ \\
\hline \multicolumn{5}{|l|}{ p16 } \\
\hline Low expression & $90(91.8)$ & $8(8.2)$ & & \\
\hline High expression & $42(79.2)$ & $11(20.8)$ & 0.026 & $2.9(1.104-7.863)$ \\
\hline \multicolumn{5}{|l|}{$R b$} \\
\hline Low expression & $76(93.8)$ & $5(6.2)$ & & \\
\hline High expression & $56(80.0)$ & $14(20.0)$ & 0.011 & $3.8(1.293-11.166)$ \\
\hline
\end{tabular}

monoclonal antibodies, DO7 and Pab240 (mutant specific), which showed some prominent differences in expression pattern. The staining intensity and positivity were comparatively more with DO7 than with PAb240. A total of $5.3 \%$ of cases were negative and $72.0 \%$ showed intense staining with
DO7 clone. However, when PAb240 clone was used, $40.4 \%$ of cases showed negative staining and only $29.8 \%$ of cases showed intense staining. This could be due to DO7 detecting both mutant and wild type p53, whereas, PAb240 detects only mutant protein under non-denaturing condition. The expression of 


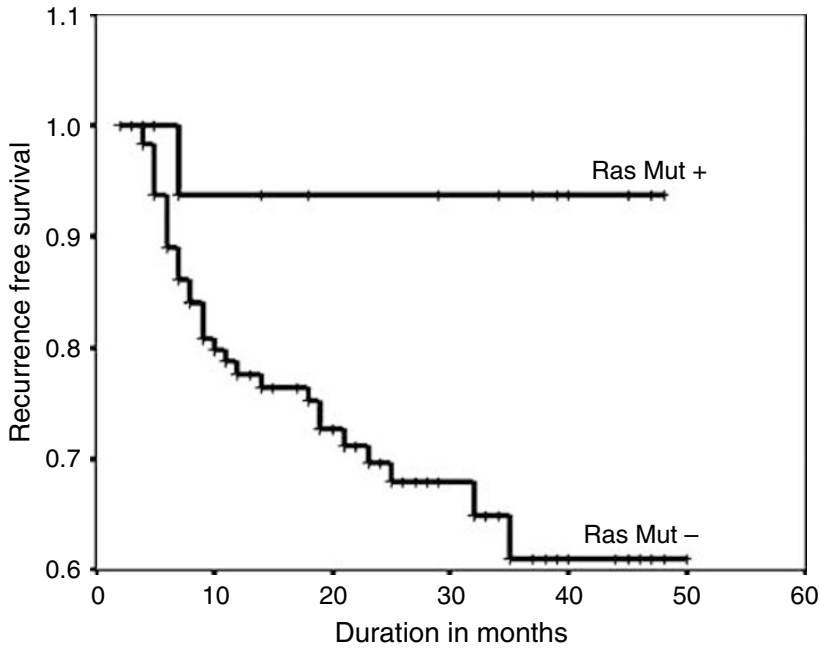

Figure 3 Kaplan-Meier recurrence-free survival curve of patients with oral carcinoma dichotomized according to H-Ras mutation. Ras-Mut ${ }^{+}$- patients with H-Ras mutation and Ras-Mut ${ }^{-}-$ patients without H-Ras mutation. Log-rank test $P=0.033$.

PCNA was not only confined to the basaloid cells, but was also seen in differentiating squamous cells. Majority of the samples showed intense (92.4\%) expression of PCNA. We have analysed the association between the expressions of cell cycle regulatory proteins and $\mathrm{H}$-Ras mutation after dichotomizing the expression data with median of expression index. H-Ras mutation showed significant association with cyclin D1 $(P=0.027)$, CDK4 $(P=0.046), \mathrm{Rb}$ $(P=0.011)$ and p16 $(P=0.026)$ expression (Table 3$)$. The expression of cyclin D1 and CDK4 was significantly low and that of p16 and Rb was high in H-Ras mutant cases. H-Ras mutation did not show any association with the expression of p53 (with both clones), p21 and PCNA.

\section{Discussion}

Ras genes are crucial regulators of several aspects of normal growth and transformation and have been reported to be mutated in $20-35 \%$ of Indian oral carcinomas. ${ }^{5,6,8-10}$ The H-Ras found to be mutated in $12.5 \%$ of the cases in the present study. In spite of $12.5 \%$ of $\mathrm{H}$-Ras mutation, the present study demonstrated lack of activating B-Raf mutation in the Indian oral carcinoma. H-Ras mutation showed significant association with low expression of $\mathrm{G}_{1}$ cell cycle regulatory proteins cyclin D1 and CDK4 and overexpression of $\mathrm{p} 16$ and Rb proteins. Moreover, the survival analysis revealed that H-Ras mutation associated with high recurrence-free survival in these patients.

The Ras-Raf-MEK-ERK-MAP kinase pathway is a well-characterized signalling pathway that couples cellular response to growth signals. Activating mutations of the Ras gene is a relatively frequent event in oral carcinogenesis in Indian patients. Previous studies from three different parts of India showed variation in Ras mutation both in terms of percentage and types of Ras genes involved. ${ }^{8-10} \mathrm{~A}$ study from southern India showed mutation in H-Ras gene $(17 \%)$ and $\mathrm{N}$-Ras $(2 \%) .^{9}$ In the present study (Southern most Indian population) $12.5 \%$ of the samples showed H-Ras mutation. There is also divergence in the afflicted codon in all these studies. These differences might be due to demographic variation. In the present study, despite $12.5 \%$ of the samples showing H-Ras mutation, we could not find mutations in B-Raf gene. The present study constitutes the first study of B-Raf mutations in a large series of HNSCC of a single anatomic siteoral cavity. It is also noteworthy that the present study included oral cancer patients from an area that has relatively high Ras mutation. A study, which investigated B-Raf mutation in head and neck carcinoma also, did not find mutation in oral cancer samples. ${ }^{14}$ Lack of B-Raf mutation could be due to specificity of carcinogens, which might target Ras gene rather than Ras pathway in oral carcinogenesis.

The Ras-Raf-MEK-ERK signal transduction pathway regulates cell-cycle progression in diverse cell types by modulating transcription factors. ${ }^{5}$ Ras acts at different phases of the cell cycle, including early $\mathrm{G}_{1}$, the $\mathrm{G}_{1} / \mathrm{S}$ boundary and at $\mathrm{G}_{2} / \mathrm{M}^{28}$ Among the major $G_{1}$ cell cycle regulatory proteins analysed, cyclin D1, CDK4, p16 and Rb showed significant association with H-Ras mutation. Several studies found that Ras activation results in increased levels of cyclin D1. ${ }^{19}$ Ras signalling also plays an important role in the assembly of cyclin D1 and CDK4 or $6 .{ }^{29} \mathrm{In}$ this context the observed low expression of cyclin D1 in tumours with H-Ras mutation is indeed surprising. In vitro experiments suggest that oncogenic Ras inhibits cell cycle by the induction of the cyclin-dependent kinase inhibitors, p16 and p21 in primary cells. ${ }^{17}$ Cells expressing oncogenic Ras and dominant negative p53 are able to proliferate in the absence of mitogen, but are unable to proliferate in the absence of anchorage and are contact inhibited. Either loss of p16 or inactivation of the Rb family makes them anchorage independent and avoid contact inhibition. ${ }^{18}$ These studies, thus, demonstrate the likely importance of p16 and Rb in the Ras-mediated transformation. ${ }^{18}$ Recently, Williams et $a l^{30}$ reported that loss of the $\mathrm{Rb}$ tumour suppressor leads to a proliferative disadvantage in tumour cell harbouring activating mutation in the Ras gene. The observed overexpression of $\mathrm{Rb}$ in the Ras-mutated cases may provide a favourable environment for Ras-mediated oncogenesis. At the same time, Rasmediated upregulation of p16 and downregulation of cyclin D1 and CDK4 may guard against the oncogenic potential of Ras by maintaining an antiproliferative response to continuous strong activation of Ras. ${ }^{18}$ In a previous study, we have reported that high expression of p16 and downregulation of cyclin D1 associated with favourable outcome in oral carcinoma. ${ }^{21}$ The molecular phenotype associated with $\mathrm{H}$-Ras mutation, thus, might reduce the 
oncogenic potential of Ras genes and provide a survival advantage for this subset of patients. Consistent with the above-mentioned possibilities, we demonstrated a survival advantage in patients with H-Ras mutation. The present study, thus, points to a direct interaction between H-Ras mutation and G1 cell cycle regulatory protein in tumours in vivo and provides the impetus for additional studies in this direction not only in oral carcinoma but also in other types of tumours.

Analysis between genders showed significant difference in the distribution of H-Ras mutation. Females showed a higher rate of H-Ras mutations (Table 3). The odds ratio (OR) for paan chewing was more elevated among women oral cancer patients (OR 42; 95\% CI 24-76) than among men in one study from southern India. ${ }^{31}$ Majority of the observed mutations ( $\mathrm{G}>\mathrm{A}$ transitions (13/20-65\%) followed by $\mathrm{G}>\mathrm{T}$ transversion $(4 / 20-20 \%)$ ) in the present study was reported to be attributed to the exposure to tobacco-derived carcinogens. ${ }^{32}$ Therefore, the high prevalence of tobacco-chewing habits among women might be the reason for the observed high rate of H-Ras mutation among women. The tongue and buccal mucosal carcinoma is reported to be biologically distinct. ${ }^{33}$ Similarly, here we also found a difference in the distribution of H-Ras mutation between tongue and other oral sites, reaffirming our previous results. ${ }^{33}$ This suggests an aetiological and biological difference in the carcinogenesis of the different intra-oral sites. Even though Ras mutation is moderately high in Indian oral cancer scenario; none of the studies investigated its prognostic potential. The present study demonstrated that oral carcinoma with H-Ras mutation represent a unique molecular subtype with favourable prognosis. Similar to the present study, Ras overexpression was reported to be associated with favourable prognosis in HNSCC, ${ }^{34}$ although, conflicting reports are also available. ${ }^{35}$

In summary, the present study demonstrated that H-Ras mutation associated with expression of key cell cycle regulatory proteins such as cyclin D1, $\mathrm{CDK} 4, \mathrm{Rb}$ and $\mathrm{p} 16$ in vivo. It seems that molecular phenotype associated with mutant Ras guard against the oncogenic potential of H-Ras mutation in oral carcinoma and thus provide favourable prognosis to the patients. Similar to this proposed theory, surprisingly, H-Ras mutation predicts favourable prognosis in this patient population. Such an interaction between $\mathrm{H}$-Ras mutation and cell cycle regulatory proteins should be reconfirmed in larger number of samples. Thus, H-Ras mutation defines a molecular subtype of oral carcinoma with favourable outcome and unique biology.

\section{Acknowledgements}

We express special thanks to Dr Andrea Tannapfel, Leipzig University of Medicine, Germany, Dr
Barabara L Weber, Abramson Family Cancer Research Institute, Philadelphia and Dr James A Fagin, University of Cincinnati College of Medicine, Ohio for kindly providing positive controls for BRAF mutation analysis. We are also thankful to Dr D Karunagaran, Rajiv Gandhi Centre for Biotechnology, Thiruvananthapuram, for providing SW480 cell lines. The present study was financially supported by the Kerala State Council for Science, Technology and Environment, Government of Kerala through their Grant no. (T)201/SRS/2005/ CSTE. KM Sathyan is a recipient of Senior Research Fellowship of Council for Scientific and Industrial Research, Government of India.

\section{References}

1 Parkin DM, Whelan SL, Ferlay J, et al. (eds). Cancer Incidence in Five Continents. IARC Press: Lyon, 2002.

2 Johnson N. Tobacco use and oral cancer: a global perspective. J Dent Educ 2001;65:328-339.

3 Paterson IC, Eveson JW, Prime SS. Molecular changes in oral cancer may reflect aetiology and ethnic origin. Eur J Cancer B Oral Oncol 1996;32B:150-153.

4 Silverman Jr S. Demographics and occurrence of oral and pharyngeal cancers. The outcomes, the trends, the challenge. J Am Dent Assoc 2001;132(Suppl):7S-11S.

5 Chang F, Steelman LS, Shelton JG, et al. Regulation of cell cycle progression and apoptosis by the Ras/ Raf/MEK/ERK pathway (Review). Int J Oncol 2003;22: 469-480.

6 Downward J. Targeting RAS signalling pathways in cancer therapy. Nat Rev Cancer 2003;3:11-22.

7 Adjei AA. Ras signaling pathway proteins as therapeutic targets. Curr Pharm Des 2001;7:1581-1594.

8 Das N, Majumder J, DasGupta UB. Ras gene mutations in oral cancer in eastern India. Oral Oncol 2000;36: 76-80.

9 Munirajan AK, Mohanprasad BK, Shanmugam G, et al. Detection of a rare point mutation at codon 59 and relatively high incidence of $\mathrm{H}$-ras mutation in Indian oral cancer. Int J Oncol 1998;13:971-974.

10 Saranath D, Chang SE, Bhoite LT, et al. High frequency mutation in codons 12 and 61 of H-ras oncogene in chewing tobacco-related human oral carcinoma in India. Br J Cancer 1991;63:573-578.

11 Chang SE, Bhatia P, Johnson NW, et al. Ras mutations in United Kingdom examples of oral malignancies are infrequent. Int J Cancer 1991;48:409-412.

$12 \mathrm{Xu}$ J, Gimenez-Conti IB, Cunningham JE, et al. Alterations of p53, cyclin D1, Rb, and H-ras in human oral carcinomas related to tobacco use. Cancer 1998;83:204-212.

13 Davies H, Bignell GR, Cox C, et al. Mutations of the BRAF gene in human cancer. Nature 2002;417: 949-954.

14 Weber A, Langhanki L, Sommerer F, et al. Mutations of the BRAF gene in squamous cell carcinoma of the head and neck. Oncogene 2003;22:4757-4759.

15 Franza Jr BR, Maruyama K, Garrels JI, Ruley HE. In vitro establishment is not a sufficient prerequisite for transformation by activated Ras oncogenes. Cell 1986;44:409-418. 
16 Hirakawa T, Ruley HE. Rescue of cells from Ras oncogene-induced growth arrest by a second, complementing, oncogene. Proc Natl Acad Sci USA 1988;85: 1519-1523.

17 Serrano M, Lin AW, McCurrach ME, et al. Oncogenic Ras provokes premature cell senescence associated with accumulation of p53 and p16INK4a. Cell 1997;88:593-602.

18 Mitchell PJ, Perez-Nadales E, Malcolm DS, et al. Dissecting the contribution of p16(INK4A) and the $\mathrm{Rb}$ family to the Ras transformed phenotype. Mol Cell Biol 2003;23:2530-2542.

19 Filmus J, Robles AI, Shi W, et al. Induction of cyclin D1 overexpression by activated ras. Oncogene 1994;9:3627-3633.

20 Bardeesy N, Bastian BC, Hezel A, et al. Dual inactivation of RB and p53 pathways in RAS-induced melanomas. Mol Cell Biol 2001;21:2144-2153.

21 Jayasurya R, Sathyan KM, Lakshminarayanan K, et al. Phenotypic alterations in $\mathrm{Rb}$ pathway have more prognostic influence than p53 pathway proteins in oral carcinoma. Mod Pathol 2005;18:1056-1066.

22 Kimura ET, Nikiforova MN, Zhu Z, et al. High prevalence of BRAF mutations in thyroid cancer: genetic evidence for constitutive activation of the RET/PTC-RAS-BRAF signaling pathway in papillary thyroid carcinoma. Cancer Res 2003;63:1454-1457.

23 Nikiforova MN, Lynch RA, Biddinger PW, et al. RAS point mutations and PAX8-PPAR gamma rearrangement in thyroid tumors: evidence for distinct molecular pathways in thyroid follicular carcinoma. J Clin Endocrinol Metab 2003;88:2318-2326.

24 Knowles MA, Williamson M. Mutation of H-Ras is infrequent in bladder cancer: confirmation by singlestrand conformation polymorphism analysis, designed restriction fragment length polymorphisms, and direct sequencing. Cancer Res 1993;53:133-139.

25 Servomaa K, Kiuru A, Kosma VM, et al. p53 and K-ras gene mutations in carcinoma of the rectum among Finnish women. Mol Pathol 2000;53:24-30.
26 Omholt K, Karsberg S, Platz A, et al. Screening of N-ras codon 61 mutations in paired primary and metastatic cutaneous melanomas: mutations occur early and persist throughout tumor progression. Clin Cancer Res 2002;8:3468-3474.

27 Garcia-Rostan G, Zhao H, Camp RL, et al. Ras mutations are associated with aggressive tumor phenotypes and poor prognosis in thyroid cancer. J Clin Oncol 2003;21:3226-3235.

28 Winston JT, Coats SR, Wang YZ, et al. Regulation of the cell cycle machinery by oncogenic ras. Oncogene 1996;12:127-134.

29 Cheng M, Sexl V, Sherr CJ, et al. Assembly of cyclin D-dependent kinase and titration of p27Kip1 regulated by mitogen-activated protein kinase kinase (MEK1). Proc Natl Acad Sci USA 1998;95: 1091-1096.

30 Williams JP, Stewart T, Li B, et al. The retinoblastoma protein is required for Ras-induced oncogenic transformation. Mol Cell Biol 2006;26: 1170-1182.

31 Balaram P, Sridhar H, Rajkumar T, et al. Oral cancer in southern India: the influence of smoking, drinking, paan-chewing and oral hygiene. Int $\mathrm{J}$ Cancer 2002;98:440-445.

32 Hoffmann D, Hecht SS. Nicotine-derived $N$-nitrosamines and tobacco-related cancer: current status and future directions. Cancer Res 1985;45:935-944.

33 Sathyan KM, Sailasree R, Jayasurya R, et al. Carcinoma of tongue and the buccal mucosa represent different biological subentities of the oral carcinoma. J Cancer Res Clin Oncol 2006;132:601-609.

34 Kiaris H, Spandidos DA, Jones AS, et al. Mutations, expression and genomic instability of the H-ras protooncogene in squamous cell carcinomas of the head and neck. Br J Cancer 1995;72:123-128.

35 Coutinho CM, Bassini AS, Gutierrez LG, et al. Genetic alterations in Ki-ras and Ha-ras genes in juvenile nasopharyngeal angiofibromas and head and neck cancer. Sao Paulo Med J 1999;117:113-120. 